\title{
EXPERIMENTAL STUDY OF INFLUENCE OF TUYERE BELT DESIGN ON THERMAL CONDITIONS OF GASIFICATION CHAMBER OPERATION
}

\author{
Nataliya Tsyvenkova ${ }^{1,2}$, Savelii Kukharets ${ }^{1}$, Valentina Kukharets ${ }^{1}$, Nataliya Savchenko ${ }^{1}$ \\ ${ }^{1}$ Zhytomyr National Agroecological University, Ukraine; ${ }^{2}$ National University of Life and \\ Environmental Sciences of Ukraine, Ukraine \\ nataliyatsyvenkova@gmail.com, saveliy_76@ukr.net, lidanaz@ukr.net, \\ nataliyasavchenko2010@ukr.net
}

\begin{abstract}
The work is devoted to investigation of dependence of gasification chamber service time on their operating temperature conditions. To investigate this, two, different in tuyere belt design, gasification chambers were used. A scheme of laboratory installation and a method of chamber wall temperature measurement are presented. Experiments were done to estimate the influence of parameters, such as the tuyere belt design of the gasification chamber, operation modes of the gasifier on the gasification chamber wall temperature. It was substantiated that high temperature of the chamber walls that reaches $1020^{\circ} \mathrm{C}$, substantial temperature gradient of walls that in particular cases can reach $578^{\circ} \mathrm{C}$ and continued influence of high temperature combined with mechanical tension are the reasons of thermal tensions in the chamber walls and their strength decreasing. It was noticed that starting the gasifier is the most stressful operating mode because of maximal temperature gradient. Independently from the operational mode the most stressed sections of the gasification chamber are located in the tuyere belt and neck. Experiments proved that installing 10 tuyeres in two levels instead of 5 in one level resulted in more even temperature distribution in the chamber walls in tuyere plane. When we installed 10 tuyeres instead of 5 , the temperature difference between the upper and narrow parts of the chamber in the vertical direction dropped from $490{ }^{\circ} \mathrm{C}$ to $360^{\circ} \mathrm{C}$ for gas consumption of $68 \mathrm{~m}^{3} \cdot \mathrm{h}^{-1}$. In the horizontal direction the maximal temperature difference in the tuyere belt, at gas consumption of $44 \mathrm{~m}^{3} \cdot \mathrm{h}^{-1}$, was $215^{\circ} \mathrm{C}$ and $182^{\circ} \mathrm{C}$, respectively. In summary it raised the chamber service time.
\end{abstract}

Keywords: gasifier, syngas, service time, temperature, tensions.

\section{Introduction}

An experience of exploitation of gasifiers on biomass fuels testifies that the gasifier significant disadvantage is low service life of its main assembly a gasification chamber $[1 ; 2]$. This flaw makes gasifier exploitation difficult and expensive [3]. It is also known that the main reason of the gasification chamber malfunctioning is harsh temperature conditions, such as high temperature in the active zone reaching up to $1500{ }^{\circ} \mathrm{C}[2 ; 3]$; big difference in temperature of closely located points of the gasification chamber [4]; instability of the chamber wall temperature; prolonged influence of high temperature on the chamber parts $[5 ; 6]$. Within the gasifier operational temperature range, material resistance to plastic deformations and destruction decreases [7].

Meanwhile, harsh temperature conditions of the gasification chamber surfaces at higher temperatures are not studied enough, as well as the kinetics of their appearance.

Analysis of gasification chambers shows that the main defects of the chambers are: warping of the upper part of shell [2;5], lower part surface oxidation [8], neck diameter narrowing $[9 ; 10]$ and cracks in narrow parts of upper and lower cones [11].

Multiple tries to raise the service life of gasification chambers by use of heat resistant steel with high chrome and nickel content did not show great results because of absence of the full picture about the chamber operational temperature conditions [7-9]. Thus, study of temperature conditions of operation and raising the service life of gasification chambers is a relevant problem.

The aim of the investigation is studying thermal conditions of a downdraft gasifier gasification chamber operation to choose the optimal chamber design with prolonged service life. The one that provides the minimal difference between maximal and minimal temperature in control points is considered optimal.

\section{Materials and methods}

These studies were performed in on a gas producing installation of the Zhytomyr National Agroecological University, Fig 1. The experimental installation consists of a downdraft gasifier with productivity $60-68 \mathrm{~m}^{3} \cdot \mathrm{h}^{-1}$, gas purification and gas cooling system, vacuum pump VVN-12/0.4 as gas consumer imitating equipment, equipment to record temperature of the gasification chamber walls, 
equipment to observe the process of gasification and installation parts operation. The chamber wall temperature was measured with the type $\mathrm{K}$ thermocouple. Temperature recording was done with an electronic thermometer NKTECH MPR-9815. Measurements were transferred to a PC for processing.

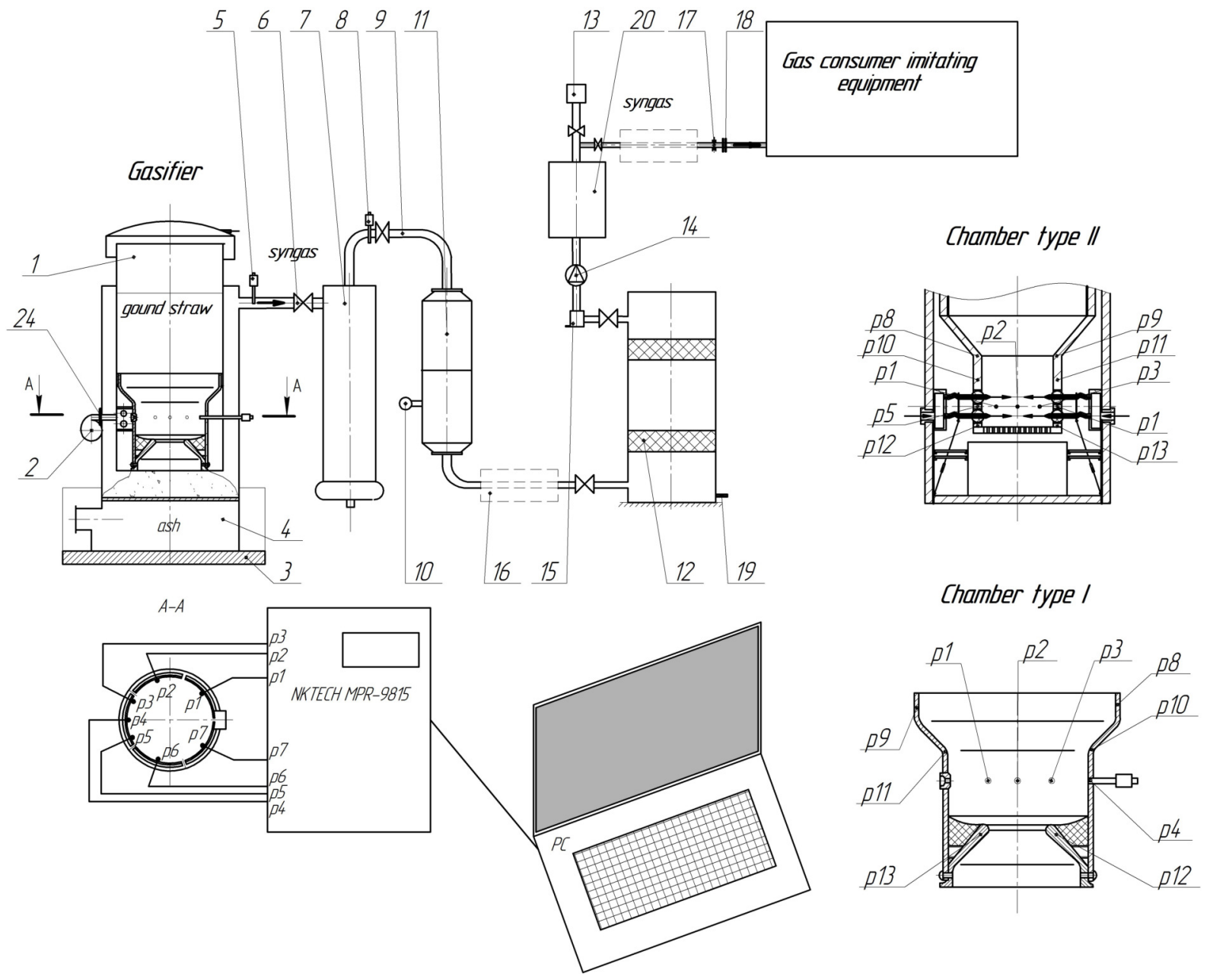

Fig. 1. Experimental installation drawing: 1 - downdraft gasifier; 2 - double stage blower (GHBH 00434 2R5 3KW); 3 - laboratory scales TVE 500-10 according to DSTU EN 45501; 4 - bunker for ash; 5, 8 - type K thermocouple; 6 - pipe valve; 7 - cyclone scrubber; 9 - gas pipe; 10 - type $\mathrm{C}$ thermocouple; 11 - cooler; 12 - module of fine purification; 13 - calorimeter CM6G; 14 - vacuum pump; 15 - moisture extractor for separation water steam from gas; 16 - gas sampling assembly;

17 - throttle washer for regulation of gas supply; 18 - choke; 19 - condensate drain tube;

20 - receiver; p1-p13 - thermocouple installation points in the gasifier chamber parts

Experiments were performed with two types of gasification chambers - chamber type I and chamber type II that are shown in Fig. 1. Assembly drawing of the gasification chamber type I is shown in Fig. 2a. The gasification chamber casing was welded, inlay was cast. The chamber casing was made of C45 steel, 8mm thick. Inlay - cast from H25N20S2 steel. Air was fed separately to each tuyere. There are 5 tuyeres $10 \mathrm{~mm}$ in diameter and $25 \mathrm{~mm}$ in length.

The design of the gasification chamber type II is different from the gasification chamber type I by the design of the tuyere belt and absence of the lower cone. The tuyere belt consist of two levels with 5 tuyeres each with the same dimensions as before. Such design provides more even air flow in the gasification zone.

The sequence of actions was as follows. The first experiment was performed on the gasification chamber type I, which is shown in Fig. 2a. There were 13 type-K thermocouples installed on the surface of the chamber parts. The points of thermocouple installation are shown in Fig. 1 (marked as p.1-p.13). The thermocouple installation method in the chamber wall was realized according to [7] and is shown in Fig. 2b. Then the chamber was mounted into the downdraft gasifier. The bunker was 
filled with fuel and the gasifier was started. Wheat straw pellets were used as a fuel. The pellet quality corresponds to DIN 51731 and ONorm M 7135 standards [6].

The gasifier starting time varied between 18-20 min. Overall operation time on one load is 320 min. Temperature measurements were performed under such operational modes: gasifier kindling; stable operational mode (full load of gas consumption $68 \mathrm{~m}^{3} \cdot \mathrm{h}^{-1}$ ); gradual decreasing of gas consumption (65-44\% load of gas consumption); sharp change in gas consumption from maximal to minimal and vice versa; stop of gas consumption (cooling of the gasification chamber when the pump operation stopped).

a)

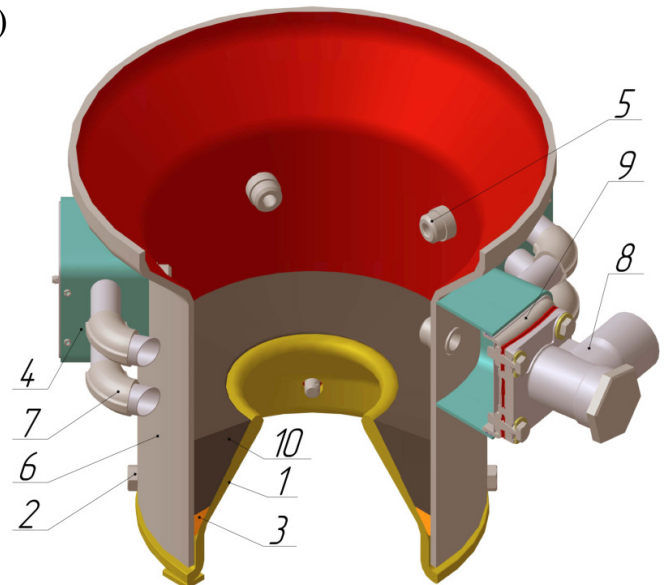

b)

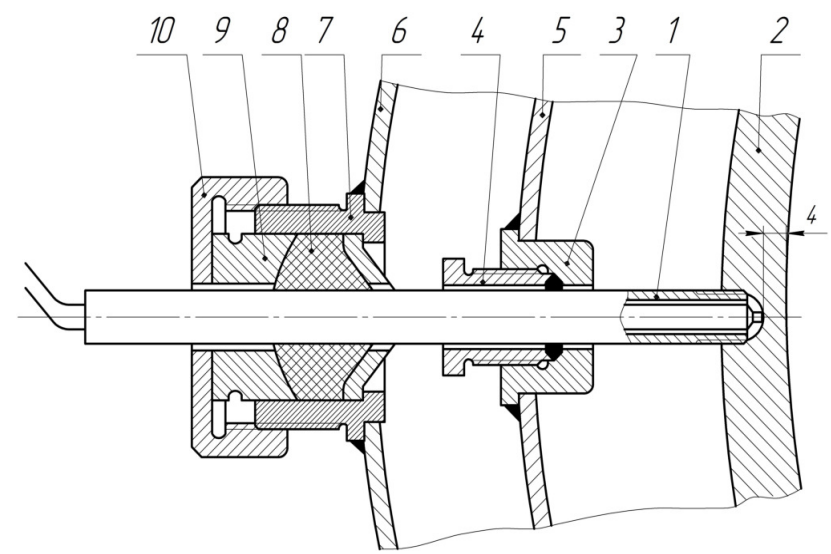

Fig. 2. Experimental gasification chamber type I: $a-\mathrm{CAD}$ model ( 1 - chamber inlay made of H25N20S2 steel; 2 - supporting bolt; 3 - asbestos rope sealant; 4 - air distribution box; 5 - tuyere; 6 - chamber casing; 7 - air feeding pipe; 8 - tube socket; 9 - air feeding box lid; 10 - chamber inset); $b$ - thermocouple installation in gasification chamber wall ( 1 - type $\mathrm{K}$ thermocouple; 2 - gasification chamber; 3 - steel bushing; 4 - fitting; 5 - air feeding channel wall; 6 - gasifier casing;

$$
7 \text { - fitting; } 8 \text { - asbestos seal; } 9 \text { - bushing; } 10 \text { - nut) }
$$

The presented method of thermocouple installation in Fig. $2 \mathrm{~b}$ provides a possibility to quickly change them in case of failure during the experiment. This provided continuous wall temperature recording. After stop the gasifier was left to cool down completely. Then new load of fuel was put in and the experiment repeated. Number of experiments for gasification chamber type I is 5 . Then the chamber type I was dismounted.

To investigate the influence of the chamber design on its thermal operational conditions a gasification chamber type II made from C45 steel was used, Fig. 1. A chamber with installed according to Fig. 2b, thermocouples were mounted into the gasifier casing. Experiments were performed according to the method described above. Number of repetitions was also 5.

Experimental data were processed with "Statistica". The error of the experiment was calculated only for stable mode of operation, which is characterized by constant gas composition and heat value. There is no possibility to calculate the error for modes of kindling and stopping because of significant number of uncontrolled factors that influence the process. According to the plan of the experiment the values of the model relative error are lower than 3.7\% [12]. This is the case for all experiment. The values of mean relative deviation are lower than $2.3 \%$ [12]. Thus, the relative error value is less than $10 \%$ [12]. Such relative error value is considered acceptable in modelling. Therefore, it can be concluded that the presented model predicts the thermal conditions of the gasification chamber operation with high accuracy.

\section{Results and discussion}

In the process of gasification of solid fuels exo- and endothermic reactions occur in the active layer. As a result of domination of exothermic reactions, a significant quantity of heat is excreted and the temperature in a fuel layer in gasification chamber (in the gasification chamber neck) reaches up to $1500{ }^{\circ} \mathrm{C}$. The temperature of the gasification chamber walls and its variation character during the gasifier operation was defined experimentally, Fig. 3. 
According to Fig. 3, the chamber neck walls are the hottest parts. This could be explained by the fact that the gas flow is narrowed in the neck and thus heat is concentrated. Thanks to the higher temperature in the neck, there are the necessary conditions for pyrolysis of tar components of dry fuel distilling, which have not cracked in the active zone of gasification. In the chamber type I design (Fig. 2a) a neck is made to make possible gasification of bitumen containing types of fuel (wood).

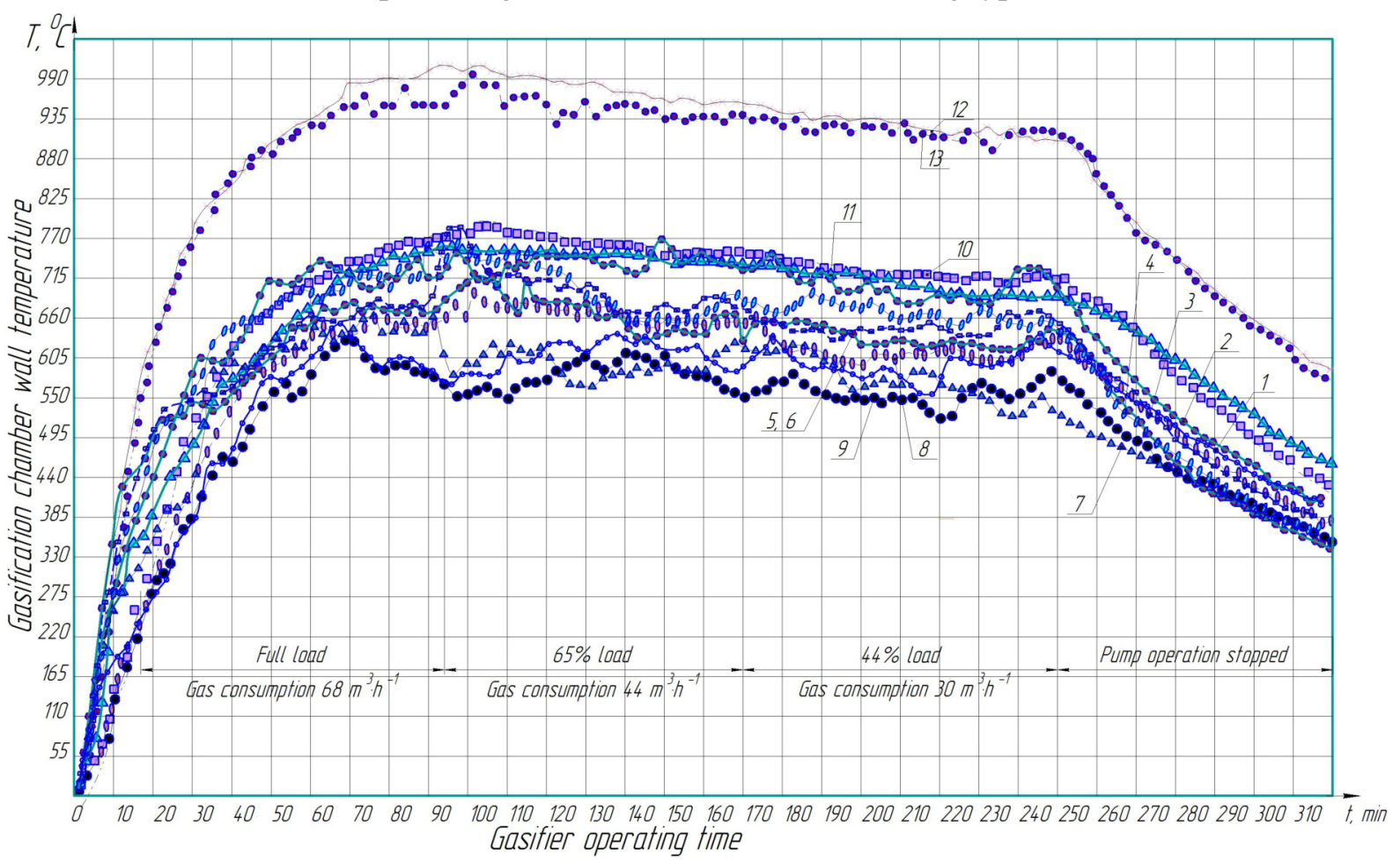

\section{Fig. 3. Dependence of chamber part temperature on time and mode of gasifier operation Chamber type I}

During gasification of straw pellets the chamber inlay neck wall temperature reached $1020^{\circ} \mathrm{C}$. According to Fig. 3, on all operational modes a significant temperature variation of the chamber walls, as in vertical direction so in horizontal, was observed. If we explore the unevenness of the chamber wall heating in vertical direction, then, according to Fig. 3, a temperature difference between the upper and narrow parts of the chamber casing at gas consumption of $68 \mathrm{~m}^{3} \cdot \mathrm{h}^{-1}$ was $490{ }^{\circ} \mathrm{C}$, Fig. 3 (points 9 and 13). If we look at the unevenness of the chamber wall temperature in horizontal direction, then the maximal difference in the tuyere belt at gas consumption of $44 \mathrm{~m}^{3} \cdot \mathrm{h}^{-1}$, was $215^{\circ} \mathrm{C}$, Fig. 3 (points 4 and 7).

Uneven temperature distribution in solid body causes thermal stresses. They are inner by nature. Hence, uneven heating and cooling that took place in the chamber walls at all operational modes are the reason of inner stresses. There are no other sources of stresses, except the temperature difference, influencing the gasification chamber, because there are no outer forces acting on the gasification chamber. As the temperature difference builds up in different directions, the parts of the gasification chamber are experiencing an added stress condition. Also, at temperatures higher than $550{ }^{\circ} \mathrm{C}$ a creep deformation is intensified in both carbon and heat resistant steels. Within the range of operational temperatures of the gasifier a resistance of the chamber material to plastic flow as well as destruction is decreasing.

According to the research, during gasifier kindling the biggest temperature difference is created in the walls of the chamber neck. It is due to difference in the heating speed of different parts of the chamber wall. Within first 5 minutes the mean speed of heating in the flange of the upper part of the chamber was $27^{\circ} \mathrm{C} \cdot \mathrm{min}^{-1}$, while in the walls of its narrow part it was $126^{\circ} \mathrm{C} \cdot \mathrm{min}^{-1}$.

In the points p. 12 and p., 13 Fig. 3 , during the kindling process the temperature difference was $578^{\circ} \mathrm{C}$, while at a stable mode $-412^{\circ} \mathrm{C}$. 
The dependence of the chamber part temperature from the time and mode of the gasifier operation for the chamber type II is given in Fig. 4.

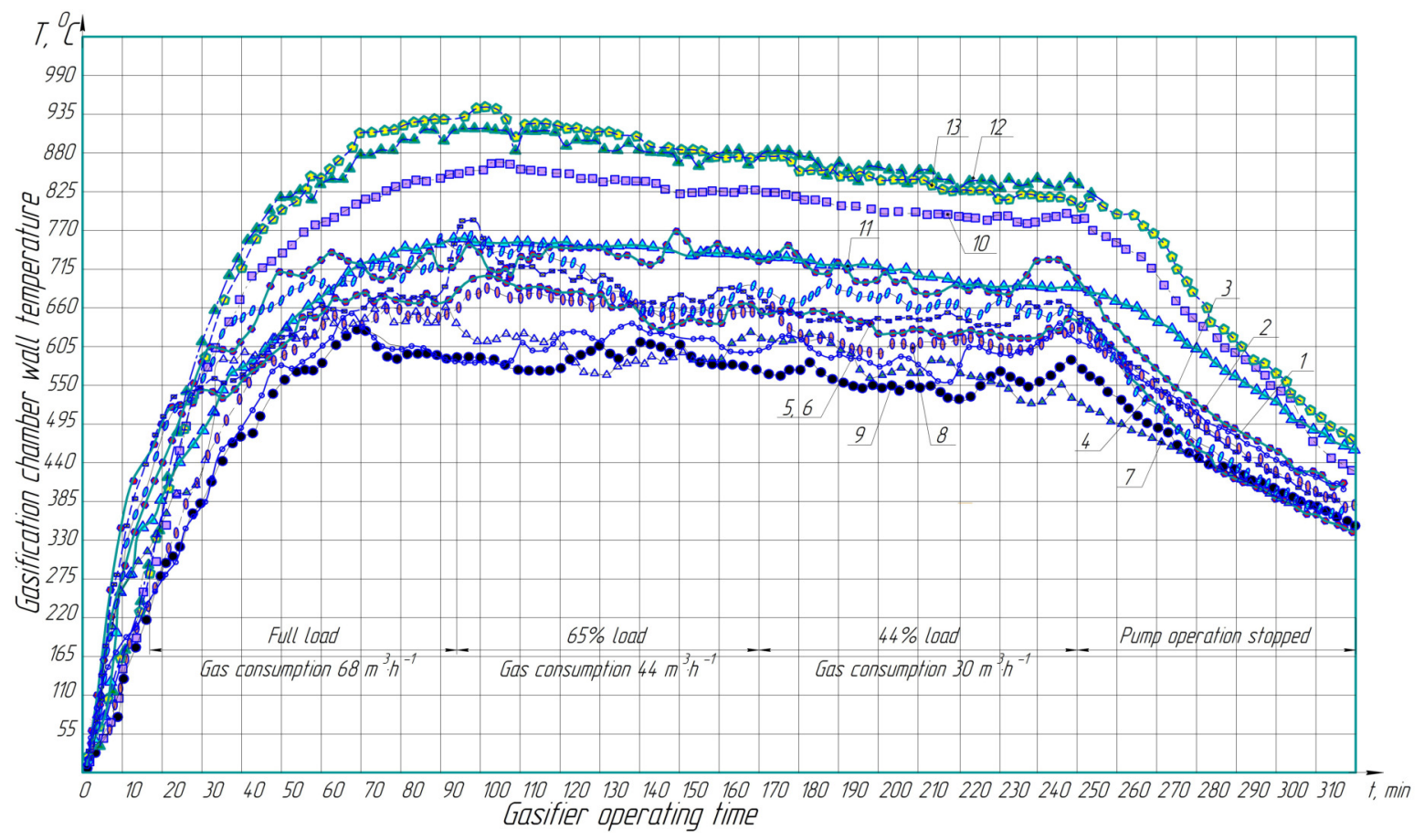

Fig. 4. Dependence of chamber part temperature ob time and mode of gasifier operation Chamber type II

According to Fig. 4, the temperature difference in the walls of the chamber type II is significantly lower than of the chamber type I, Fig. 3. If we explore the unevenness of the chamber wall heating in vertical direction, then, according to Fig. 4, the temperature difference between the upper and narrow parts of the chamber casing at gas consumption of $68 \mathrm{~m}^{3} \cdot \mathrm{h}^{-1}$ was $360{ }^{\circ} \mathrm{C}$, Fig. 4 (points 9 and 13). If we look at the unevenness of the chamber wall temperature in horizontal direction, then the maximal difference, in the tuyere belt at gas consumption of $44 \mathrm{~m}^{3} \cdot \mathrm{h}^{-1}$, was $182^{\circ} \mathrm{C}$, Fig. 4 (points 4 and 7). For the chamber type II within first 5 minutes the mean speed of heating in the flange of the upper part of the chamber was $23^{\circ} \mathrm{C} \cdot \mathrm{min}^{-1}$, while in the walls of its narrow part it was $117^{\circ} \mathrm{C} \cdot \mathrm{min}^{-1}$.

The influence of alternating gasifying mode on the wall temperature also was investigated. Transfers from maximal gas consumption to minimal and vice versa, total stop of gas consumption do not result in abrupt change of the camera wall temperature. This is due to thermal inertia of the chamber walls and the fuel layer. Within the first 5 minutes the speed of temperature increasing in the neck walls was $19^{\circ} \mathrm{C} \cdot \mathrm{min}^{-1}$ (for chamber type I) and $15^{\circ} \mathrm{C} \cdot \mathrm{min}^{-1}$ (for chamber type II), when changing the gas consumption from 25 to $68 \mathrm{~m}^{3} \cdot \mathrm{h}^{-1}$. When decreasing the gas consumption from 68 to $25 \mathrm{~m}^{3} \cdot \mathrm{h}^{-1}$ the speed of temperature dropping was less than $16^{\circ} \mathrm{C} \cdot \mathrm{min}^{-1}$ (for chamber type I) and $14^{\circ} \mathrm{C} \cdot \mathrm{min}^{-1}$ (for chamber type II). The variation of the wall temperature for both chambers was less than $1{ }^{\circ} \mathrm{C} \cdot \mathrm{min}^{-1}$. When changing the gas consumption gradually from 68 to $44 \mathrm{~m}^{3} \cdot \mathrm{h}^{-1}-$ the inlay wall temperature dropped only for $34-38{ }^{\circ} \mathrm{C}$ (chamber type I) and for $27-30{ }^{\circ} \mathrm{C}$ (chamber type II) during an hour. For cooling after full stop of gas consumption a gradual decreasing of temperature is typical.

Fig. 3, Fig. 4 illustrate that gasifier kindling is the most stressful mode for the chamber neck. The reason is the maximal wall temperature difference (hence maximal stress) before the chamber material is not plastic enough. This explains separate cases of cracking of the neck part of chambers after the first start. Straw is characterized by high momentary temperature surges when starting fire and burns quickly. Temperature variation in the straw layer during kindling has a sinusoidal shape, which again increases the thermal stress in the chamber part walls.

According to Fig. 3, Fig. 4, the maximal temperature difference (maximal tension) for the most part of the cycle was recorded between thermocouples 8 and 9,12 and 13. Thermocouples 8 and 9 are installed in the upper part of the tuyere belt, thermocouples 12 and 13 - in the gasification chamber 
neck. High temperature in points 12 and 13 is caused by the heat stream carried by syngas. Exactly this temperature difference initiates significant thermal stresses, which destruct metal. This explains deformations and cracks that are seen on heavily used gasification chambers.

Change of temperature difference of the gasification chamber walls with 5 and 10 tuyeres during the full cycle of operation (320min) are shown in Fig. 5.

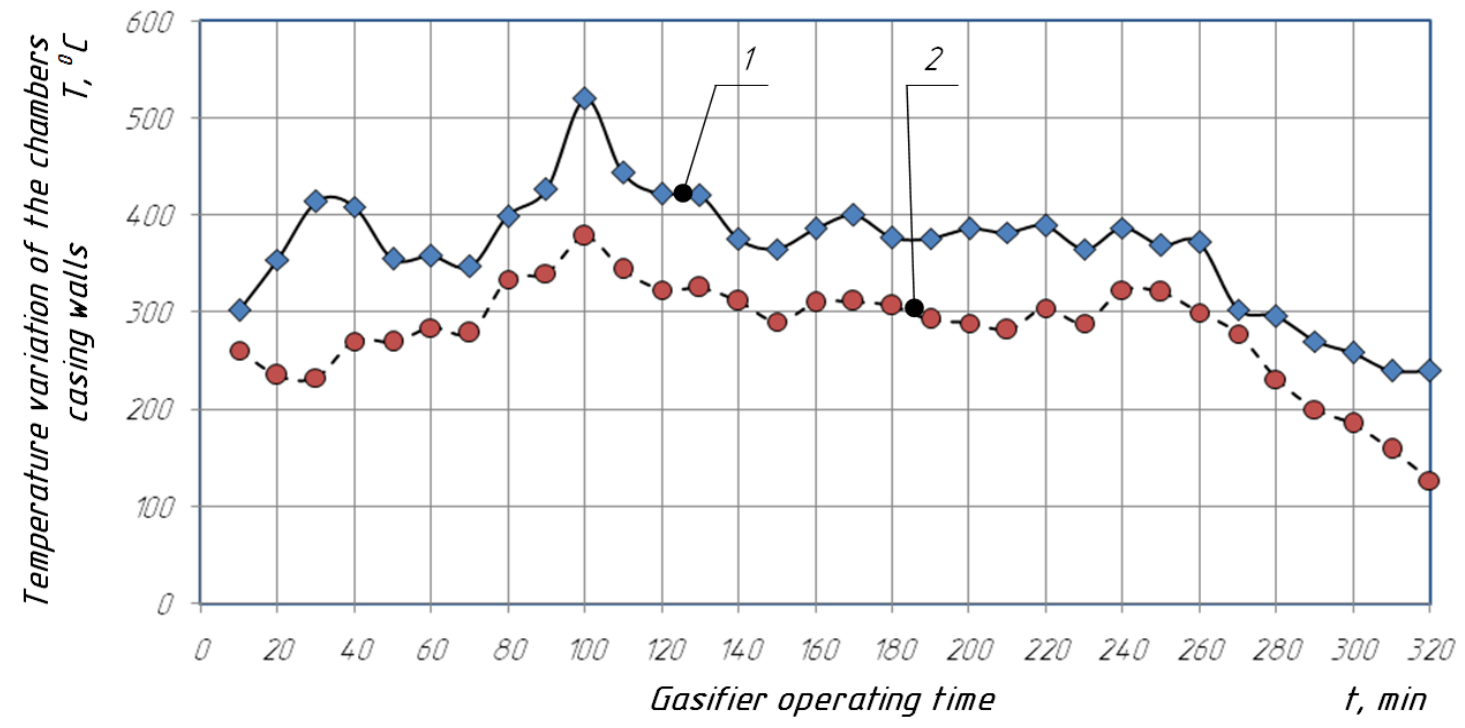

Fig. 5. Change of temperature difference in walls of both gasification chambers:

1 - chamber type I; 2 - chamber type II

Both experiments show similar temperature distribution, the only difference is between points 8 and 9, 12 and 13. In a modified chamber type II, according to Fig. 5, the maximal temperature difference is $378{ }^{\circ} \mathrm{C}$ on min100, i.e. during the stable mode. Meanwhile, in the original design the maximal temperature difference is $520^{\circ} \mathrm{C}$ on min 100 of the operational cycle. Thus, the chamber design change lowers the temperature difference by $38 \%$, consequently reducing thermal stresses significantly. Mean temperature difference across all cycle for the original design is $366^{\circ} \mathrm{C}$, and for the modified design $281^{\circ} \mathrm{C}$. Temperature distribution in the chamber walls in the tuyere section shows a distinct regularity: the further from the air feeding box, the higher the temperature. It is due to intensive cooling of the part of the chamber casing wall near the air feeding box by air fed to the chamber. According to Fig. 3, Fig. 4, despite the mode a continuous wall temperature fluctuation is observed. This causes thermal aging and intensifies deformation and destruction of the chamber parts. Under the influence of alternating tangential stresses primal microcracks appear in the metal; further, after stress cycling, they grow and associate with each other into macrocrack. Primal microcrack usually appears on the surface that is the most stressed part. Then it develops into depth, until alternating stress will lead to brittle destruction. The investigation results of heating unevenness and temperature instability lead to a conclusion that the most stressed section of the chamber is the tuyere belt, despite the fact that the wall temperature there is $150-200{ }^{\circ} \mathrm{C}$ lower than in other points of the chamber. Operational conditions are characterized by prolonged action of high temperature on stressed parts of the chamber that degrades its mechanical strength.

Let us look at the influence of gas consumption on the wall temperature. Raising the gas consumption from 44 to $68 \mathrm{~m}^{3} \cdot \mathrm{h}^{-1}$ results in increasing chamber wall temperature, Fig. 3, in the tuyere section from 660 to $715^{\circ} \mathrm{C}$, that is only $55^{\circ} \mathrm{C}$. And $48{ }^{\circ} \mathrm{C}$ for the chamber type II, Fig. 4 . Albeit it is enough to decrease the strength parameters of material and, hence, to cause the chamber deformation. It is possible to lower the chamber wall temperature by increasing the chamber diameter, but this means more steel is needed and also outer dimensions of the gasifier also rise.

Temperature conditions of the gasifier operation on wood and coal are reviewed in $[7 ; 9 ; 14]$. We received higher values of the temperature difference and temperature itself, when investigating temperature conditions of the downdraft gasifier operation on straw pellets. This is due to difference in the physical and chemical specifications of straw from bitumen containing fuels. 
The study results of temperature conditions of the chamber operation on different gasifier modes and knowledge about the most stressed sections of its parts make possible to formulate principles of further gasification chamber design improvement.

\section{Conclusions}

Investigation of the gasification chamber wall temperature of a downdraft gasifier made possible to determine the temperature conditions of its operation.

1. As a result of prolonged influence of temperatures reaching as high as $1020^{\circ} \mathrm{C}$, a significant degradation of strength of the chamber parts is observed. Temperature difference, that in some cases reaches $578{ }^{\circ} \mathrm{C}$, is a source of temperature stresses. Periodical heating and cooling is a source of thermal fatigue of the material. High temperature and temperature difference of the chamber walls are the most influent factors that affect its service life.

2. Installing 10 tuyeres in two levels instead of 5 in one level resulted in more even temperature distribution in the chamber walls in the tuyere plane. The temperature difference between upper and lower parts of the chamber in vertical direction dropped from $490{ }^{\circ} \mathrm{C}$ to $360{ }^{\circ} \mathrm{C}$ for gas consumption of $68 \mathrm{~m}^{3} \cdot \mathrm{h}^{-1}$. In horizontal direction the maximal temperature difference in the tuyere belt, at gas consumption of $44 \mathrm{~m}^{3} \cdot \mathrm{h}^{-1}$, dropped from $215^{\circ} \mathrm{C}$ to $182^{\circ} \mathrm{C}$. Relief in operational temperature conditions raised the chamber service life.

3. Investigation of operational temperature conditions of the gasification chamber on different operational modes and knowledge about the most stressed sections of its parts are the required initial data. These data made it possible to formulate principles of further gasification chamber design improvement. The received results could be used for further investigations in direction of increasing the gasification chamber service life.

\section{References}

[1] Basu P. Biomass gasification, pyrolysis and torrefaction: practical design and theory. Third edition. Elsevier, 2018. 564 p. DOI: 10.1016/C2016-0-04056-1

[2] Kukharets S., Tsyvenkova N., Yarosh Ya. etc. The results of study into the effect of air-steam blast on the low-grade fuel gasification process. Eastern-European Journal of Enterprise Technologies, vol. 6, No. 8(96), 2018, pp. 86-96.

[3] Susastriawan A.A.P., Saptoad H., Purnomo. Small-scale downdraft gasifiers for biomass gasification: A review. Renewable and Sustainable Energy Reviews, vol. 76, 2017, pp. 989-1003.

[4] Reed T., Das A. Handbook of Biomass Downdraft Gasifier Engine Systems. Golden: Solar Energy Research Institute, 1988. 140 p. DOI: 10.2172/5206099

[5] Mezin I.S. Influence of gasification chamber height and diameter on gas composition (Влияние диаметра и высоты камеры газификации на химический состав газа), Works of the Design and experimental institute of transport industry. Moscow: Mashgiz, vol 40, 1941. $156 \mathrm{p}$.

[6] Golub G., Kukharets S., Tsyvenkova N., etc. Experimental study into the influence of straw content in fuel on parameters of generator gas. Eastern-European Journal of Enterprise Technologies, vol. 5, No. 8, 2018, pp. 76-86. DOI: 10.15587/1729-4061.2018.142159

[7] Мезин И.С. Транспортные газогенераторы (Automotive gas producers). Moskow: Ogiz Selhozgiz, 1948, 311 p. (In Russian).

[8] Frandsen R.B., Montgomery M., Larsen Ol. H. Field test corrosion experiences when co-firing straw and coal: 10 year status within Elsam. Materials at High Temperatures, 24(4), 2007, pp. 343-349. DOI: 10.3184/096034007X278365

[9] Юдушкин Н. Г., Артамонов М. Д. Газогенераторные тракторы. Теория, конструкция и расчет : науч. изд. (Gas producer on tractors. Theory, design and calculations). Moskow: GOSNTIML, 1955, 244 p. (In Russian).

[10] De Sousa L.C., Hütter P., Mayor J. C. etc. Fluidized Bed Reactor for the Gasification of Biomass: Annual Report. General Energy Technology, Paul Scherrer Institut, 1994, Annex V, 129 p.

[11] Generator Gas. The Swedish experience from 1939-1945: Translated by the Solar energy Research Instityte. Golden, Colorado, 1979.

[12] Мельников С.В., Ацелкин В.Р., Рощин П.М. Планирование эксперимента в исследованиях сельскохозяйственных процессов (An experiment planning in researches of agricultural processes). Leningrad: Kolos, 1980, 168 p. (In Russian). 